Wien Klin Wochenschr (2016) · 128:226-226

DOI 10.1007/s00508-016-0995-8

C) Springer-Verlag Wien 2016

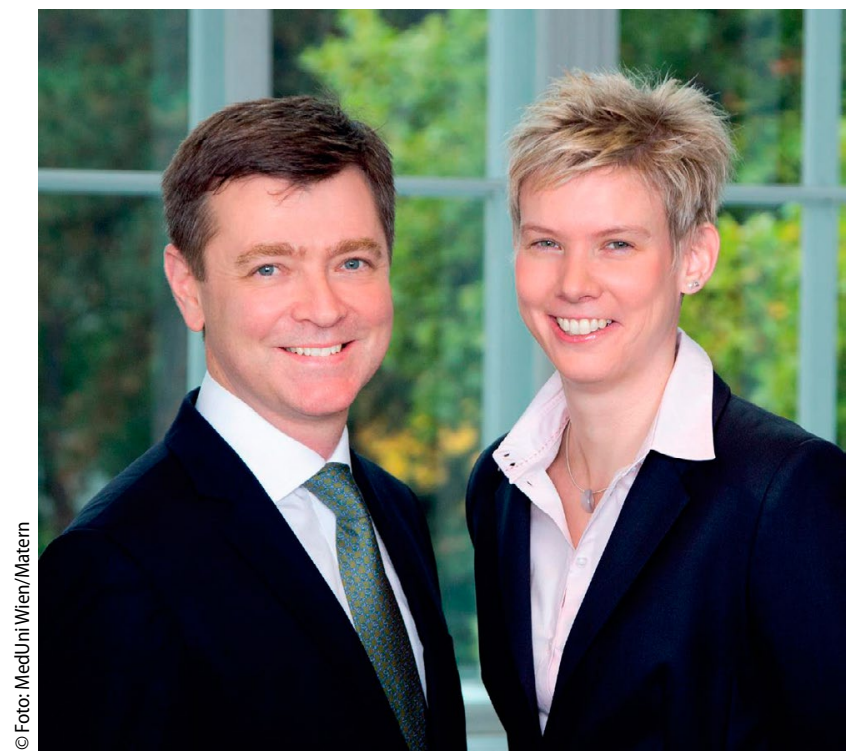

\section{Antrittsvorlesung zweier neuer Professoren an der Universitätszahnklinik Wien}

Am 29. Jänner 2016 fanden an der Universitätszahnklinik in einem gemeinsamen feierlichen Akt zwei Antrittsvorlesungen statt. Nach einführenden Worten des Rektors der Medizinischen Universität Wien, Markus Müller, und des Geschäftsführers der Universitätszahnklinik Wien, Andreas Moritz, folgten die Laudationes. Für Frau Professor Katrin Bekes gehalten von Hans-Günter Schaller (Martin-Luther-Universität Halle-Wittenberg), für Professor Reinhard Gruber gehalten vom ehemaligen Vorstand der Universitätszahnklinik Georg Watzek.

Katrin Bekes hatte ihre Stelle bereits am 1. April 2015 als Professorin für Zahn-, Mund- und Kieferheilkunde des Kindesalters angetreten. Ihr Forschungsschwerpunkt ist die Lebensqualitätsforschung, worauf sie auch in ihrer Rede „Wurzeln schlagen“ einging. Sie arbeitet an der Entwicklung und Evaluierung von deutschsprachigen Instrumenten zur Erfassung der mundgesundheitsbezogenen Lebensqualität bei Kindern und Jugendlichen und Erwachsenen sowie deren klinischer Anwendung. Ziel ist es, den Einfluss einzelner oraler Faktoren auf die Hierarchie funktioneller, psychischer und sozialer Parameter zu beschreiben. Außerdem widmet sich Katrin Bekes der Epidemiologie der Karies, der Dentinhaftung zahnärztlicher Füllwerkstoffe im Milchgebiss und den Möglichkeiten des Einsatzes computergestützter Simulationssysteme in der zahnmedizinischen Ausbildung.

Zur Person: Prof. Bekes studierte Zahnmedizin an der Martin-Luther-Universität Halle-Wittenberg, war seit 2010 Oberärztin am Department für Zahn-, Mundund Kieferheilkunde und habilitierte sich 2012 für das Fach der Zahn-, Mund- und Kieferheilkunde mit dem Thema „Einführung und Anwendung eines Instruments zur Messung der mundgesundheitsbezogenen Lebensqualität bei Kindern und Jugendlichen. Die deutsche Version des Child Perceptions Questionnaire (CPQ-G1114): Übersetzung, psychometrische Eigenschaften und Normwerte".

Reinhard Gruber übernahm mit 1. Oktober 2014 die Professur für Orale Biologie. Die Ziele des neuen Faches sind, die translationale Forschung im Bereich der regenerativen Zahnmedizin zu etablieren und die theoretischen Grundlagen in das Zahnmedizin-Curriculum zu integrieren. Ein Schwerpunkt der wissenschaftlichen Arbeit von Prof. Gruber sind der Knochenstoffwechsel und die Bedeutung der Osteoklasten: „Die Forschungsstrategie basiert auf der Umsetzung von grundlegenden Erkenntnissen aus der Zell- und Entwicklungsbiologie, der Genetik, und der Materialforschung in die Entwicklung von kausalen Therapiestrategien in der Zahnmedizin. Beispielsweise stellt uns die Regeneration des Zahnhalteapparates oder periimplantärer Veränderungen vor eine große Herausforderung. Auch die Regeneration einer entzündeten Zahnpulpa ist noch nicht gelungen. Die Zusammenhänge von Alter, systemischen Erkrankungen wie Osteoporose und Diabetes, sowie von Medikamenten im Bereich der Zahnmedizin sind nur teilweise bekannt und ein weiterer strategischer Forschungsschwerpunkt.“ Prof. Gruber ist als Gastwissenschaftler am Bone Tissue Engineering Center an der Carnegie Mellon University in Pittsburgh sowie an der Dental School der University of Michigan, USA, tätig, gründet das interdisziplinäre Doktorandenprogramm „Bone and Joint Regeneration“ und fungiert in internationalen Prüfungskommissionen. Ein großes Anliegen war und ist ihm die Aus- und Weiterbildung, folgerichtig war der Titel seiner Antrittsvorlesung „Lehre durch Forschung“.

Zur Person: Reinhard Gruber ist verheiratet und hat zwei Kinder. Wie viele klugen Köpfe wuchs er in Baden auf, absolvierte das Gymnasium in der Biondekgasse und studierte danach Lebensmittel- und Biotechnologie an der Universität für Bodenkultur in Wien. Er wurde an der Medizinischen Universität Wien promoviert und wechselte 1999 an die Abteilung für Orale Chirurgie der Universitätszahnklinik Wien. 2004 wird ihm die Venia docendi für Zellbiologie erteilt. Im Jahr 2012 wurde er Leiter des Labors für Orale Zellbiologie an den Zahnmedizinischen Kliniken der Universität Bern. Er ist als Editor-in-Chief des „International Journal of Stomatologie und Occlusion Medicine" und im Editorial Board dreier internationaler zahnärztlicher Zeitschriften tätig. 